\title{
Joining of aluminium alloy and galvanized steel sheets multi- material assembly using a gas metal arc based process
}

\author{
Atanu Das ${ }^{1}$ \\ Sven-F Goecke ${ }^{2}$ \\ Amitava De $3^{*}$ (1)
}

\begin{abstract}
Fast responsive control of the heat input can minimize thermal distortion and formation of brittle intermetallic phases during gas metal arc-based joining of steel and aluminium multi-material assembly. A detailed experimental investigation and computer-based process modeling are reported here on gas metal arc based joining of automotive aluminium alloy sheets and galvanized steel sheets. The thermal cycles near the actual joint interface and the thermal distortion of the joint assembly are estimated using the computer-based model and validated with the corresponding experimentally measured results. The computed thermal cycles are utilized further to examine the experimentally measured progressive growth of the phase layer and the susceptibility of the brittle intermetallic compounds along the joint interface. Overall, the results show that a precise control of heat input can provide defect-free and dimensionally consistent joint in gas metal arc joining of aluminium to galvanized steel sheets at moderate joining speeds.
\end{abstract}

Keywords: Gas metal arc joining; Aluminium alloy; Galvanized steel; Thermal distortion.

\section{Introduction}

Joining of multi-material assemblies such as aluminium and galvanized steel sheets using conventional fusion welding processes is challenging due to their widely different thermo-physical properties [1,2]. For example, the thermal conductivity, coefficient of thermal expansion and liquidus temperature of common aluminium alloys are respectively $137 \mathrm{~W} / \mathrm{mK}, 23.5 \times 10^{-6} / \mathrm{K}$ and $952 \mathrm{~K}$ in contrast to that of steel as $46 \mathrm{~W} / \mathrm{mK}, 12.2 \times 10^{-6} / \mathrm{K}$ and $1765 \mathrm{~K}[3]$. As a result, the aluminium to steel multi-material assembly is susceptible to a large temperature gradient, and resulting thermal distortion when melting of materials occur during the selected joining process [3]. Secondly, the chemical reaction between iron and aluminium is likely at moderate temperature that results in brittle $\mathrm{Fe}_{x} \mathrm{Al}_{\mathrm{y}}$ intermetallic compounds (IMC) due to poor solubility of iron into aluminium [4]. The layer along the joint interface consisting of brittle $\mathrm{Fe}_{\mathrm{x}} \mathrm{Al}_{\mathrm{y}} \mathrm{IMC}$ becomes susceptible to cracks resulting in deterioration of the joint properties $[5,6]$. Although, the presence of zinc from the galvanized steel surface promotes wettability of the deposit from the filler wire and improves joint strength, a high energy input will lead to vaporization of zinc and inhibit an intimate contact along the joint interface [1]. Since thermal distortion, growth of the IMC and vaporization of zinc are affected by the heat input, the gas metal arc (GMA) based processes with advanced power sources, which can provide a fast responsive control of the arc power, are emerging as efficient alternatives for successful joining of aluminium alloy and galvanized steel sheets. Extensive investigations are therefore needed for the GMA-based processes with advanced power sources to become a viable technology for joining of such multi-material assemblies.

The recent studies on joining of multi-material assemblies of galvanized steel and aluminium alloy sheets highlight the importance to control the heat input to achieve defect-free, structurally sound and dimensionally consistent joints. The GMA-based joining process involves the use of a filler wire of an aluminium alloy and melting of both the filler wire and the aluminium sheet under the action of an electric arc. The steel sheet is not melted and the joint is expected to form by diffusion of aluminium (Al) and iron $(\mathrm{Fe})$ across the original joint interface. During the process, IMCs of different $\mathrm{Fe}_{\mathrm{x}} \mathrm{Al}_{\mathrm{y}}$ compositions are formed along the joint interface and the layer consisting of these IMCs is referred to as the diffusion or phase layer [1,4]. If the arc heat input is insufficient, a weak phase layer is formed with little or no joint strength [1]. In contrast, very high heat input can result in excessive growth of the phase layer and brittle IMC thereby promoting embrittlement of the joint.

Several researchers reported that a heat input of around $111 \mathrm{~J} / \mathrm{mm}$ and a subsequent $5 \mu \mathrm{m}$ to $12 \mu \mathrm{m}$ thick

${ }^{1}$ CSIR-National Metallurgical Laboratory, Jamshedpur, India.

${ }^{2}$ Technical University of Applied Sciences, Brandenburg an der Havel, Germany.

${ }^{3}$ Indian Institute of Technology Bombay, Mumbai, India.

*Corresponding author: amit@iitb.ac.in 
phase layer consisted of $\mathrm{Fe}_{2} \mathrm{Al}_{5}$ and $\mathrm{FeAl}_{3}$ IMC would provide a joint strength in the range of $75 \mathrm{MPa}$ to $188 \mathrm{MPa}$ in GMA-based joining of steel and aluminium sheets [5]. In contrast, $0.8 \mu \mathrm{m}$ to $4.5 \mu \mathrm{m}$ thick phase layer for a heat input range of $36 \mathrm{~J} / \mathrm{mm}$ to $126 \mathrm{~J} / \mathrm{mm}$ was also reported to provide a joint strength of around $200 \mathrm{MPa}$ [1]. A phase layer of $3 \mu \mathrm{m}$ to $5 \mu \mathrm{m}$ thickness with $\mathrm{Fe}_{2} \mathrm{Al}_{5} \mathrm{IMC}$ was reported for a heat input of $200 \mathrm{~J} / \mathrm{mm}$ that provided a joint strength of $200 \mathrm{MPa}$ [2]. A much thicker phase layer up to $15 \mu \mathrm{m}$ consisting of predominantly $\mathrm{FeAl}_{4.5} \mathrm{Si} \mathrm{IMC}$ was also reported for a heat input range of $63 \mathrm{~J} / \mathrm{mm}$ to $120 \mathrm{~J} / \mathrm{mm}$ [7].

The influence of heat input on thermal distortion for aluminium to galvanized steel dissimilar joints is rarely reported in published literature. Goecke et al. [8] used a GMA-based process with a fast responsive control of the arc power and reported a $25 \%$ drop in joint distortion for $1.6 \mathrm{~mm}$ thick steel sheets in comparison to the conventional GMA-based processes.

Goecke et al. [9] also carried out joining of $1 \mathrm{~mm}$ thick AA5052 alloy to $0.8 \mathrm{~mm}$ thick galvanized steel sheets and examined the effect of differential thermal distortions of aluminium and steel sheets on the soundness of the final assembly. In another study, Sun et al. [10] reported that the use of a laser beam could significantly reduce the thermal distortion as compared to the electric arc used in the GMA-based processes due to the preciseness of a focused laser beam.

The present work follows an experimental investigation and computer-based process simulation to estimate temperature fields, thermal cycles and corresponding thermomechanical distortion for joining of AA5754 alloy and hot-dip galvanized steel sheets in lap joint configuration using a GMA-based process. The computed thermal cycles near to the joining line and thermomechanical distortion of the assembly were compared with the corresponding measured results, wherever possible. The computed thermal cycles at the joint interface were used further to explain the observed growth of the phase layer and the formation of brittle Fe-Al IMC.

\section{Experimental setup}

Hot-dip galvanized steel sheets were joined with AA5754 alloy sheets in lap configuration using an advanced GMA-based process with AA4043 filler wire of $1.0 \mathrm{~mm}$ diameter, and pure argon 5.0 as a shielding gas at a flow rate of $15 \mathrm{l} / \mathrm{min}$. Table 1 presents the chemical composition of the metallic sheets and the filler wire. The thickness of both the steel and aluminium sheets were equal to $1.0 \mathrm{~mm}$. The AA5754 sheets were kept atop the steel sheets with an overlap of $15 \mathrm{~mm}$, Figure 1. The filler wire was fed at an angle of $75^{\circ}$ with the sheet top surface and along the edge of the aluminium alloy. Table 2 presents the processing conditions used in the present work.

Both the aluminium and the steel sheets were kept in place by clamping one thick flat mild steel plate on each sheet, Figure 1a. The clamping of the assembly was removed when it reached to room temperature. The schematic image of original and the distorted joint assembly is shown in Figure $1 b$.

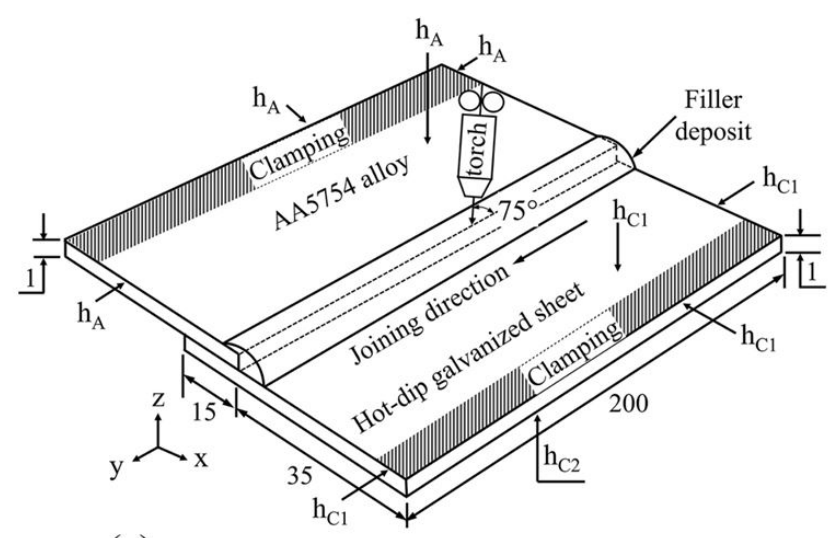

(a)

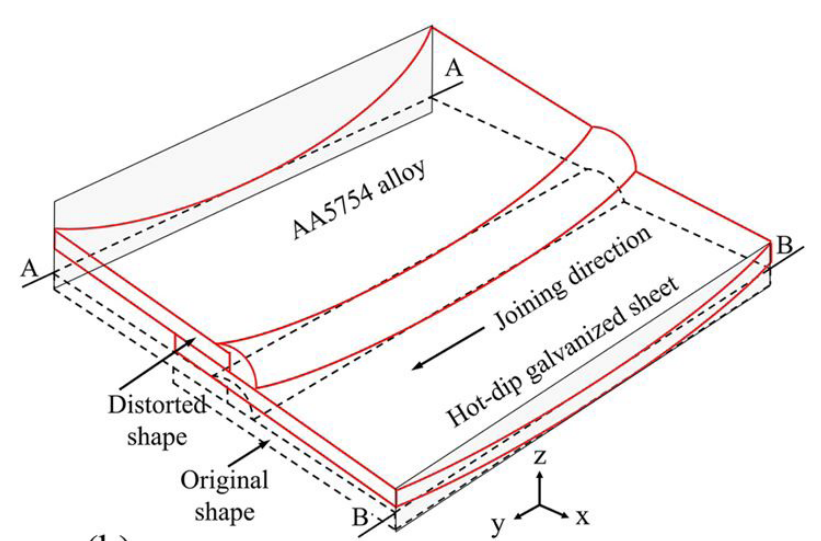

(b)

Figure 1. Schematic diagram of (a) experimental setup with the boundary conditions consider for numerical modelling and (b) induced join distortion.

Table 1. Specified chemical composition of base alloy sheets and filler wire (a single value for an element depicts the max. limit)

\begin{tabular}{lcccccccccc}
\hline & $\mathbf{M g}$ & $\mathbf{M n}$ & $\mathbf{Z n}$ & $\mathbf{F e}$ & $\mathbf{S i}$ & $\mathbf{C r}$ & $\mathbf{C u}$ & Ti & Al & $\begin{array}{c}\text { UTS in } \\
\mathbf{M P a}\end{array}$ \\
\hline AA5754 & $2.6-3.6$ & 0.50 & 0.20 & 0.40 & 0.40 & 0.30 & 0.10 & 0.15 & $\mathrm{Bal}$ & 245 \\
AA4043 (filler wire) & 0.05 & 0.05 & 0.10 & 0.80 & $4.5-6.0$ & - & 0.30 & 0.20 & $\mathrm{Bal}$ & 200 \\
& $\mathrm{C}$ & $\mathrm{Mn}$ & $\mathrm{P}$ & $\mathrm{S}$ & $\mathrm{Si}$ & $\mathrm{Cr}$ & $\mathrm{Cu}$ & $\mathrm{Ti}$ & $\mathrm{Al}$ & $\mathrm{UTS}$ in \\
& & & & & & & & & $\mathrm{MPa}$ & \\
Steel & 0.12 & 0.60 & 0.10 & 0.045 & 0.50 & - & - & 0.30 & - & 330 \\
\hline
\end{tabular}


A Zeiss Eclipse 700 coordinate measuring machine was employed to measure distortion on both aluminium and steel surface at an interval of $20 \mathrm{~mm}$ along AA and BB, respectively, Figure $1 \mathrm{~b}$.

The $\mathrm{K}$ type thermocouples were fixed along the joint line and at the bottom of the steel sheet for monitoring of the thermal cycles [11]. The transverse section of the specimens were polished with P220 to P2400 grades of emery papers, $1 \mu \mathrm{m}$ diamond grit paste and colloidal silica. The polished specimens were etched by Keller's reagent and examined under optical microscope to view the joint bead profiles. The backscatter images of the intermediate phase layer along the joint interface comprising of $\mathrm{Fe}_{\mathrm{x}} \mathrm{Al}_{\mathrm{y}} \mathrm{IMC}$ were captured employing polished sample in a CamScan 3200 scanning electron microscope. A point by point analysis of the phase layer was undertaken by Energy-dispersive X-ray spectroscopy, EDS.

\section{Theoretical modelling}

The numerically computed thermal histories of aluminium to steel multi-material assembly in lap configuration are estimated following the basic governing as Equation 1 [12]

$$
\frac{\partial}{\partial x}\left(k \frac{\partial T}{\partial x}\right)+\frac{\partial}{\partial y}\left(k \frac{\partial T}{\partial y}\right)+\frac{\partial}{\partial z}\left(k \frac{\partial T}{\partial z}\right)+\dot{Q}=\rho C_{P} \frac{\partial T}{\partial t}
$$

where $\mathrm{k}, \rho, \mathrm{C}_{\mathrm{p}}$, T and $\mathrm{t}$ depict thermal conductivity, density, specific heat, temperature and time, respectively. The term $\dot{Q}$ depicts volumetric heat generation per unit time as Equation $2[11,12]$

$$
\dot{Q}=\frac{\eta l_{A} V_{A}}{\Delta}
$$

where $\eta(\sim 0.8), \Delta, \mathrm{I}_{\mathrm{A}}, \mathrm{V}_{\mathrm{A}}$ illustrate the process efficiency, volume under the arc, average arc current and voltage, respectively. The volume under the arc is defined as the product of arc diameter and cross-sectional area of filler wire deposit profile with one element layer thickness in both aluminium and steel sheets $[11,12]$.
Figure 1a depicts the solution domain and applied boundary conditions. In Figure 1a, $\mathrm{h}_{\mathrm{A}}$ refers to the convective heat transfer coefficient along the aluminium sheet surface, and $\mathrm{hc}_{1}$ and $\mathrm{hc}_{2}$ are two lumped heat transfer coefficients along the top and bottom of the steel surfaces, respectively [11].

The estimated temperature histories are employed for a sequentially coupled thermal-mechanical analysis to calculate thermal distortion as follows [13]

$$
[K]\{d\}=\{F\},\{\delta \varepsilon\}=\left\{\delta \varepsilon_{E}\right\}+\left\{\delta \varepsilon_{P}\right\}+\left\{\delta \varepsilon_{T H}\right\}
$$

where $[\mathrm{K}]$ is the global stiffness matrix, $\{\mathrm{d}\}$ is the unknown nodal displacement vector at all nodes of solution domain and $\{\mathrm{f}\}$ stands for contribution from the thermal strain induced body force. Equation 3 will solve for $\{\mathrm{d}\}$ considering the structural boundary conditions and for given temperature gradient in two successive time-steps. Further, the non-linear elastic-plastic behavior of metallic materials are incorporated in the thermal-mechanical analysis in an incremental manner as incremental strain $(\delta \varepsilon)$ is sum of the incremental elastic $\left(\delta \varepsilon_{\mathrm{E}}\right)$, plastic $\left(\delta \varepsilon_{\mathrm{p}}\right)$, and thermal strains $\left(\delta \varepsilon_{\mathrm{TH}}\right)[13]$.

The bead profile of the filler deposit in multi-material assembly of galvanized and aluminium sheets involves the spread of the molten filler on the steel surface, the width of the fusion zone in the aluminium side and the height of the filler wire deposit along the original edge of the aluminium sheet $[11,12]$. The filler deposit profile for the modeling was estimated a-priori as function of thermo-physical properties of filler wires and process conditions [11]. Table 3 presents the mechanical properties of the sheet and filler wire materials, which are considered for the analysis. The other thermophysical properties are taken from Ref. [11].

The growth of the phase layer is estimated using the computed thermal cycles along the joint interface as follows [12]

$$
I_{i}=\sqrt{1_{i-1}^{2}+k_{0} \exp \left[-\frac{Q}{\left.R\left\{\frac{T_{i}+T_{i-1}}{2}\right\}\right]}\right]\left(t_{i}-t_{i-1}\right)}
$$

Table 2. Joining conditions considered in the present work

\begin{tabular}{cccc}
\hline Wire feed rate, WFR, in $\mathbf{~ m} / \mathbf{m i n}$ & Arc current, $\mathbf{I}_{\mathbf{A}}$, in $\mathbf{A}$ & Voltage, $\mathbf{V}_{\mathbf{A}}$, in $\mathbf{V}$ & Joining travel speed, $\mathbf{J T S}$, in $\mathbf{m m} / \mathbf{s}$ \\
\hline 4.5 & $51.15 \pm 3.47$ & $12.08 \pm 0.79$ & \\
5 & $56.18 \pm 3.72$ & $12.18 \pm 0.55$ & 12.5 \\
5.5 & $61.27 \pm 3.61$ & $12.32 \pm 0.62$ & \\
6 & $66.20 \pm 3.43$ & $12.83 \pm 0.58$ & \\
\hline
\end{tabular}

Table 3. Mechanical properties of base materials and filer wire [14]

\begin{tabular}{lcc}
\hline \multicolumn{1}{c}{ Property } & Aluminium & Steel \\
\hline Coefficient of thermal expansion in $1 / \mathrm{K}$ & $1.85 \times 10^{-5}+5.47 \times 10^{-9} \mathrm{~T}+4.89 \times 10^{-11} \mathrm{~T}^{2}-5.04 \times 10^{-14} \mathrm{~T}^{3}$ & $4.95 \times 10^{-6}+2.57 \times 10^{-8} \mathrm{~T}-1.5 \times 10^{-11} \mathrm{~T}^{2}+3.97 \times 10^{-16} \mathrm{~T}^{3}$ \\
Young Modulus in GPa & $81.34-0.041 \mathrm{~T}+1.89 \times 10^{-6} \mathrm{~T}^{2}+1.39 \times 10^{-8} \mathrm{~T}^{3}$ & $217.92+0.04 \mathrm{~T}-1.87 \times 10^{-4} \mathrm{~T}^{2}+7.16 \times 10^{-8} \mathrm{~T}^{3}$ \\
Poisson's ratio & 0.33887 & $0.28+1.26 \times 10^{-5} \mathrm{~T}+4.28 \times 10^{-8} \mathrm{~T}^{2}-2.42 \times 10^{-11} \mathrm{~T}^{3}$ \\
Yield strength in MPa & $-288.17+4.15 \mathrm{~T}-1.05 \times 10^{-2} \mathrm{~T}^{2}+7.55 \times 10^{-6} \mathrm{~T}^{3}$ & $63.08+1.97 \mathrm{~T}-3.68 \times 10^{-3} \mathrm{~T}^{2}+1.77 \times 10^{-6} \mathrm{~T}^{3}$ \\
\hline
\end{tabular}


where $l_{i}$ and $l_{i-1}$ are the phase layer thicknesses corresponding to the time instants $t_{i}$ and $t_{i-1}$, and interface temperature $T_{i}$ and $\mathrm{T}_{\mathrm{i}-1}$. The terms $\mathrm{k}_{0}, \mathrm{Q}$ and $\mathrm{R}$ refer to pre-exponential factor, activation energy and universal gas constant, with their values as $1.32 \times 10^{2} \mathrm{~m}^{2} / \mathrm{s}, 250 \mathrm{~kJ} / \mathrm{mol}$ and $8.31 \mathrm{~J} / \mathrm{mol}$ $\mathrm{K}$, respectively $[11,12]$.

\section{Results and discussion}

\subsection{Measured and computed bead profiles}

The comparison between the computed and the measured joint profiles of aluminium to galvanized steel sheets in lap configuration for WFR of $6.0 \mathrm{~m} / \mathrm{min}$ and JTS of $12.5 \mathrm{~mm} / \mathrm{s}$ is illustrated in Figure 2. The computed bead profile is characterized by the red colored contour, which comprises the temperature isotherms above the solidus temperature of aluminium alloy of $880 \mathrm{~K}$ and below the melting temperature of steel of $1053 \mathrm{~K}$. The experimentally measured and the corresponding computed bead widths are $5.45 \mathrm{~mm}$ and $4.95 \mathrm{~mm}$, respectively. Similarly, the measured and the corresponding computed bead heights are $1.59 \mathrm{~mm}$ and $1.71 \mathrm{~mm}$, respectively.

The bead profile in Figure 2 embodies the melting of both aluminium sheet and filler wire. The steel sheet does not melt and as a result, a bonding between the steel and the molten aluminium occur by diffusion. However, an opening originated in between the aluminium and steel sheets at the root of the experimental bead profile. This is attributed to the high vapor pressure of boiling zinc and localized differential thermal expansion of the aluminium and steel sheets [1]. Figure 2 depicts a fair conformity between the measured and corresponding computed bead profiles.

\subsection{Measured and computed thermal cycles}

The numerically computed thermal cycles are validated with corresponding experimentally measured thermal cycles.
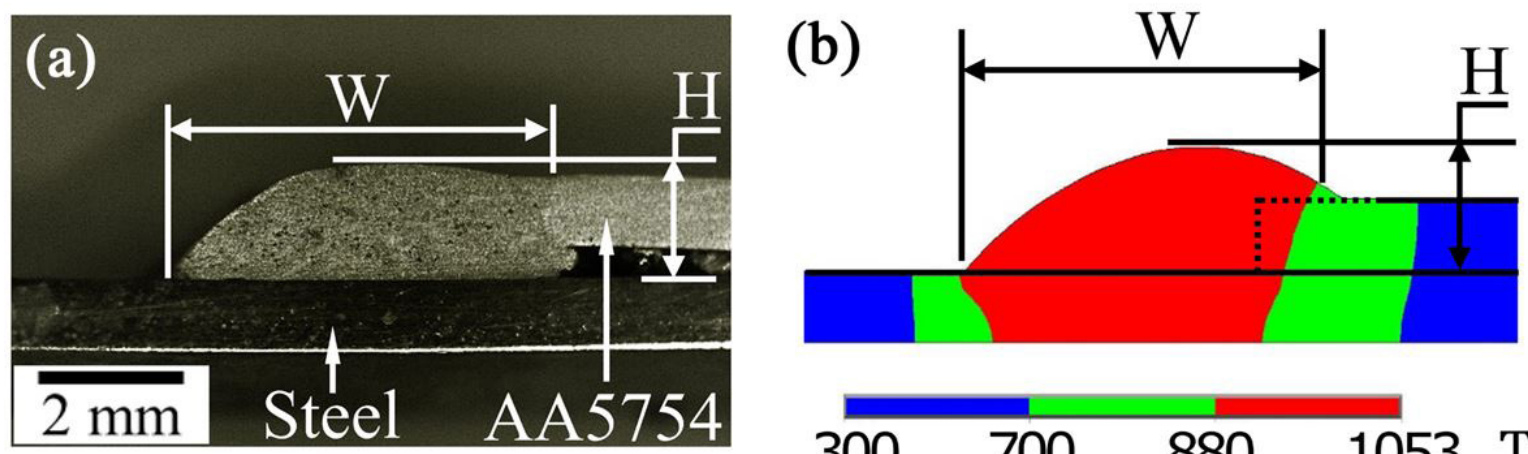

Figure 2. Comparison of (a) experimentally measured and (b) numerically computed bead profile for WFR of $6.0 \mathrm{~m} / \mathrm{min}$ and JTS of $12.5 \mathrm{~mm} / \mathrm{s}$. The measured and computed bead width, $\mathrm{W}$ and bead height, $\mathrm{H}$ are $5.45 \mathrm{~mm}, 1.59 \mathrm{~mm}$ and $4.95 \mathrm{~mm}, 1.71 \mathrm{~mm}$, respectively.
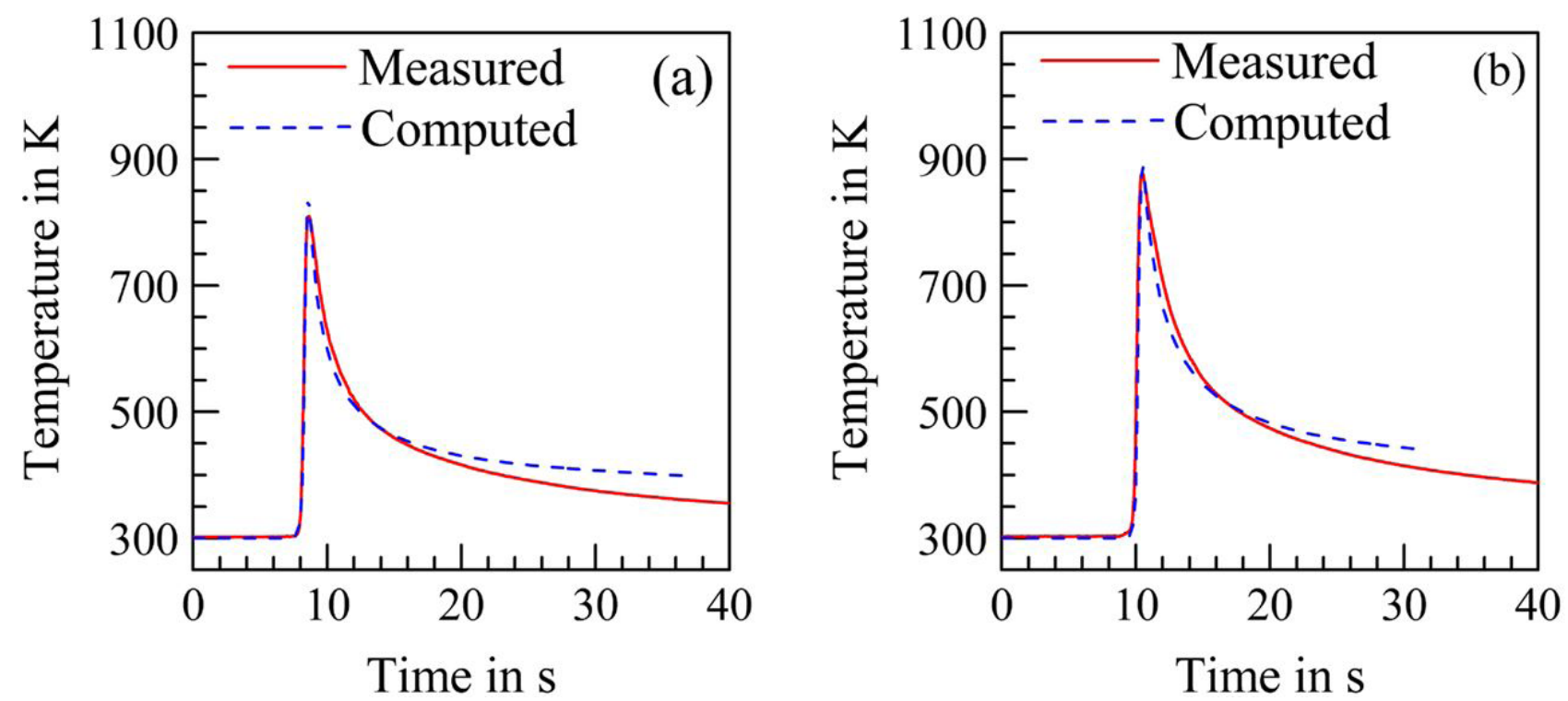

Figure 3. Comparison of measured and computed thermal cycles for different WFR of, (a) $5.0 \mathrm{~m} / \mathrm{min}$ and (b) $6.0 \mathrm{~m} / \mathrm{min}$ at a constant JTS of $12.5 \mathrm{~mm} / \mathrm{s}$. 
Figure $3 \mathrm{a}$ and $3 \mathrm{~b}$ show the measured and computed thermal cycles at constant JTS of $12.5 \mathrm{~mm} / \mathrm{s}$ for two different WFR of $5.0 \mathrm{~m} / \mathrm{min}$ and $6.0 \mathrm{~m} / \mathrm{min}$, respectively. The computed and measured values of peak temperatures are $811.8 \mathrm{~K}$ and $837.1 \mathrm{~K}$ in Figure $3 \mathrm{a}$, and $879.7 \mathrm{~K}$ and $887.7 \mathrm{~K}$ in Figure $3 \mathrm{~b}$, respectively. The corresponding heat inputs are $42.41 \mathrm{~J} / \mathrm{mm}$ and $54.30 \mathrm{~J} / \mathrm{mm}$, respectively. An increase in WFR at constant JTS results in higher heat input and peak temperature. The measured and computed thermal cycles for other process conditions exhibited similar trends.

\subsection{Measured and estimated phase layer thickness}

The thermal cycles at the joint interface were computed and utilized further to estimate the growth of the phase layer thickness for different process conditions. Figure 4a shows the estimated phase layer thickness calculated using Equation 4 and corresponding measured layer thickness for different WFR and constant JTS of $12.5 \mathrm{~mm} / \mathrm{s}$. The estimated layer thickness increased from $0.46 \mu \mathrm{m}$ to $2.69 \mu \mathrm{m}$ with increase in WFR from $4.5 \mathrm{~m} / \mathrm{min}$ to $6.0 \mathrm{~m} / \mathrm{min}$, marked by square. The corresponding measured values were in the range of $0.67 \pm 0.01 \mu \mathrm{m}$ to $2.19 \pm 0.18 \mu \mathrm{m}$, marked by circle. Thicker phase layer with increase in WFR at a constant JTS was attributed to the increase in heat input and peak temperature. The discrepancy between the computed and the measured values is attributed to the simplified form of Equation 4, which does not consider the effect of competitive growth of multiple IMCs, as well as the uncertainty arising out of the experimental measurements.

The backscatter image and EDS analysis of phase layer are shown in Figure $4 \mathrm{~b}$ and $4 \mathrm{c}$, respectively, for WFR of $5.0 \mathrm{~m} / \mathrm{min}$ and JTS of $12.5 \mathrm{~mm} / \mathrm{s}$. A cumulative average value of the measured thicknesses at various locations along the phase layer is presented here. The phase layer is continuous along the joint interface and grows with a serrated morphology towards the bead side, Figure $4 \mathrm{~b}$. The EDS based point analysis across the joint interface was carried out further to identify the concentration of $\mathrm{Al}$ and $\mathrm{Fe}$ in the phase layer. Figure $4 \mathrm{c}$ shows an increase in $\mathrm{Al}$ concentration gradient and consequent decrease of the same for Fe from the steel to aluminium side. The measured concentrations of various elements in Figure $4 \mathrm{c}$ and published literature suggest likely formation Fe-Al IMCs as $\mathrm{Fe}_{2} \mathrm{Al}_{5}$ and $\mathrm{FeAl}_{3}[1,4]$.

\subsection{Measured and computed thermal distortion}

Computed thermal distortion of the joint assembly for JTS of $12.5 \mathrm{~mm} / \mathrm{s}$ and WFR rate of $6.0 \mathrm{~m} / \mathrm{min}$ is shown in Figure 5a. A comparison between the measured and corresponding computed thermal distortion along AA and BB lines is performed for the above mentioned condition, Figure $5 \mathrm{~b}$. The measured and the corresponding computed normal distortions for the aluminium sheet along AA line are $10.5 \mathrm{~mm}$ and $7.2 \mathrm{~mm}$, respectively, Figure $5 \mathrm{~b}$. In contrast, the measured and the corresponding computed normal distortions for the steel side along the $\mathrm{BB}$ line are $2.5 \mathrm{~mm}$ and $5.2 \mathrm{~mm}$, respectively. The greater thermal distortion of the aluminium sheet as compared to that of the steel sheet is attributed to the higher thermal expansion coefficient and lower rigidity of the aluminium sheet. A fair conformity is obtained between the experimentally measured and the corresponding numerically computed thermal distortion. The little discrepancy between the measured and computed values is attributed to the use of simplified values of thermomechanical properties of the sheets at elevated temperature.

In summary, the GMA-based processes with fast responsive control of the arc heat input are fast emerging as potential techniques for joining the multi-material assemblies of aluminium to steel sheets. A prior estimation of the thermal damage during joining of the multi-material assemblies of metallic sheets using such a GMA-based process is presented here. The numerical modelling comprises of a coupled thermal-mechanical analysis for the estimation of bead profile, thermal cycles and thermal distortion. The computed values of thermal cycles are used further to estimate phase layer thickness. Overall, the estimated results indicate a fair degree of reliability with the corresponding measured results.

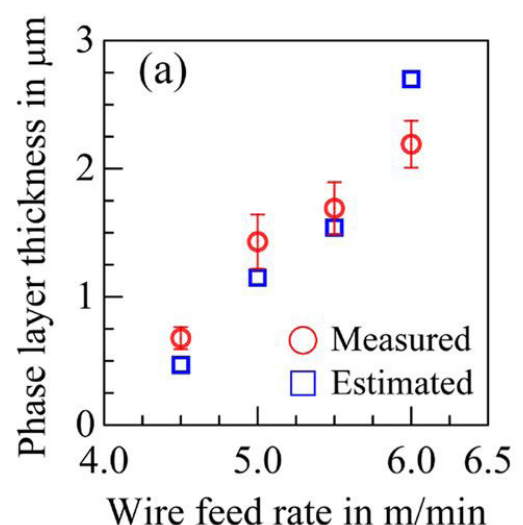

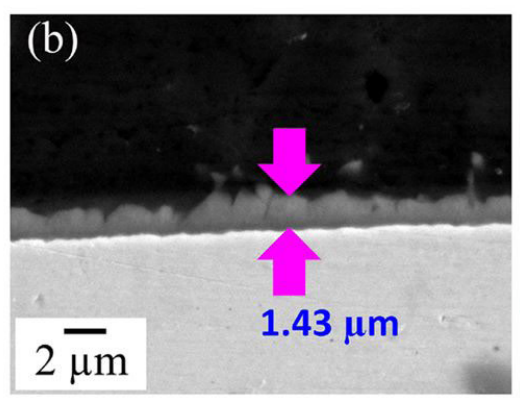

Wire feed rate in $\mathrm{m} / \mathrm{min}$

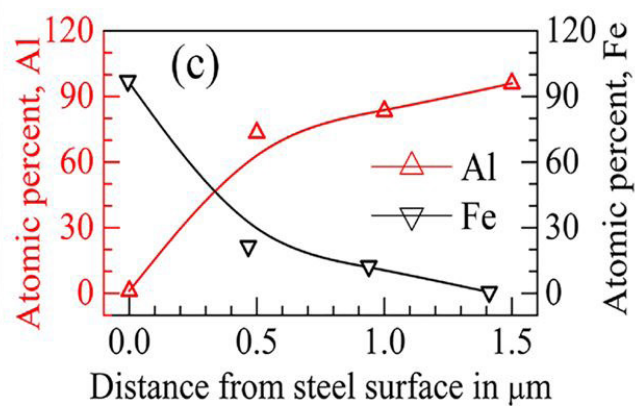

Distance from steel surface in $\mu \mathrm{m}$

Figure 4. (a) Comparison of analytically estimated and measured phase layer thickness for different WFR and JTS of $12.5 \mathrm{~m} / \mathrm{s}$; (b) Backscatter image of phase layer thickness for WFR of $5.0 \mathrm{~m} / \mathrm{min}$ and JTS of $12.5 \mathrm{~mm} / \mathrm{s}$; (c) EDS based point analysis for the phase layer of figure b. 


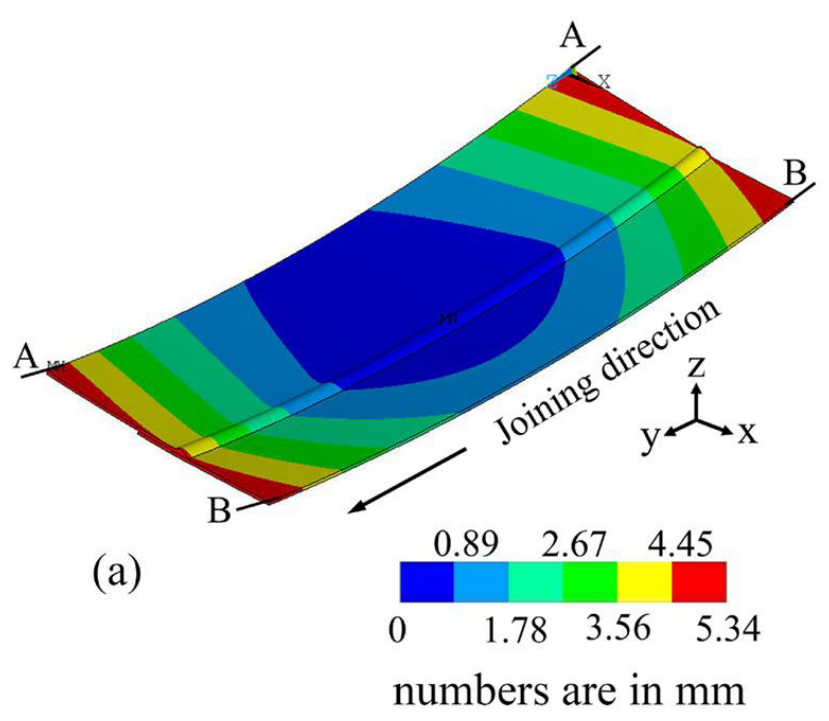

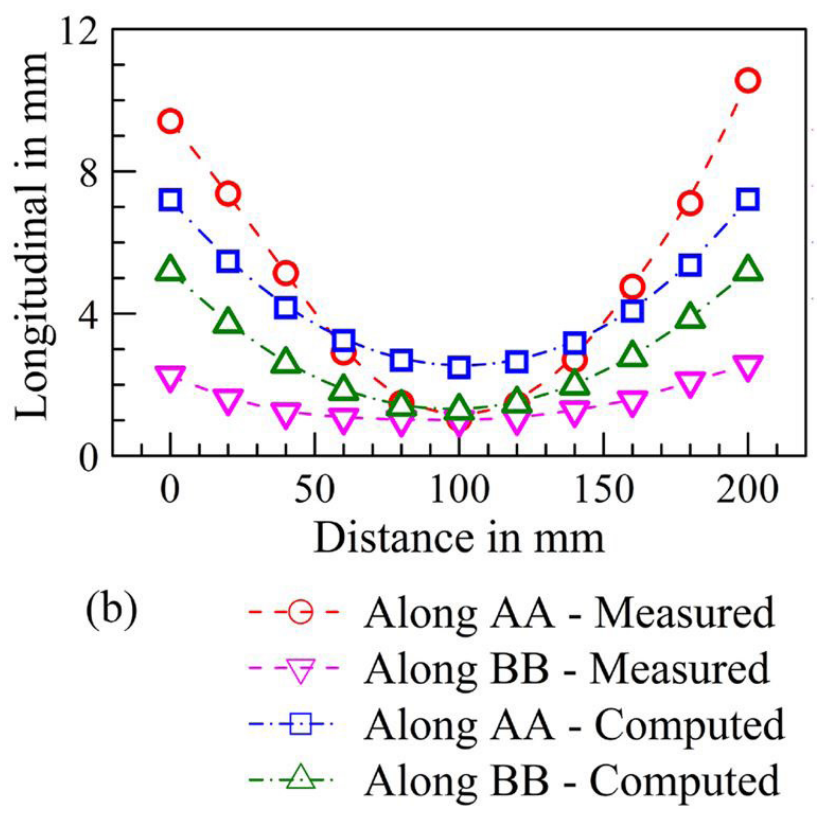

Figure 5. (a) Computed thermal distortion and (b) comparison of measured and corresponding thermal distortion along AA and BB for WFR of $6.0 \mathrm{~m} / \mathrm{min}$ and JTS of $12.5 \mathrm{~mm} / \mathrm{s}$.

\section{Conclusion}

In the present work, a methodology is introduced to estimate bead profiles, thermal cycles, growth of phase layer along the joint interface and thermal distortion for joining of multi-material assemblies of aluminium and galvanized steel sheets using a GMA-based process with fast responsive control of the arc heat input. Following conclusion are arrived at from the present work:

1. GMA-based processes with fast responsive control of the arc heat input represent a viable technology for the joining of multi-material assemblies of aluminium and galvanized steel sheets;

2. Computer based models can provide a reliable estimate of the influence of arc heat input on thermal distortion and growth of phase layer with IMCs for the joining of steel to aluminium multi-material assemblies. A precise control of the arc heat input is required to control the thermal distortion and restrict the growth of phase layer well within the acceptable limits.

\section{References}

1 Das A, Shome M, Goecke SF, De A. Joining of aluminium alloy and galvanized steel using a controlled gas metal arc process. Journal of Manufacturing Processes. 2017;27:179-187.

2 Cao R, Yu G, Chen JH, Wang PC. Cold metal transfer joining of aluminum alloys-to-galvanized mild steel. Journal of Materials Processing Technology. 2013;213:1753-1763.

3 Davis JR. Aluminium and aluminium alloy. 5th ed. Materials Park, Ohio, USA: ASM International; 1994.

4 Das A, Shome M, Das CR, Goecke SF, De A. Joining of galvannealed steel and aluminium alloy using controlled short circuiting gas metal arc welding process. Science and Technology of Welding and Joining. 2015;20:402-408.

5 Kang M, Kim C. Joining Al 5052 alloy to aluminized steel sheet using cold metal transfer process. Materials \& Design. 2015;81:95-103.

6 Yang S, Zhang J, Lian J, Lei Y. Welding of aluminum alloy to zinc coated steel by cold metal transfer. Materials \& Design. 2013;49:602-612.

7 Zhang H, Liu J. Microstructure characteristics and mechanical property of aluminum alloy/stainless steel lap joints fabricated by MIG welding-brazing process. Materials Science and Engineering A. 2011;528:6179-6185.

8 Goecke SF, Arshad AS, Spiegel EM, De A. Probing current, voltage and metal transfer characteristics in pulsed arc and in conventional and a novel low energy input short arc GMAW. Quarterly Journal of the Japan Welding Society. 2013;31:26s-30s. 
9 Goecke SF, Makwana P, Shome M, De A. Probing joint strength and distortion in gas metal arc lap joining of aluminum and steel sheets. Welding in the World. 2019;63:229-236.

10 Sun J, Liu X, Tong Y, Deng D. A comparative study on welding temperature fields, residual stress distributions and deformations induced by laser beam welding and $\mathrm{CO}_{2}$ gas arc welding. Materials \& Design. 2014;63:519-530.

11 Das A, De A. Gas metal arc lap joining of aluminium alloys and steel sheets. Journal of Welding and Joining. 2018;36:19-26.

12 Das A, Shome M, Goecke SF, De A. Numerical modelling of gas metal arc joining of aluminium alloy and galvanized steels in lap joint configuration. Science and Technology of Welding and Joining. 2016;26:303-309.

13 Tekriwal P, Mazumder J, Transient and residual thermal strain-stress analysis of GMAW. Journal of Engineering Materials and Techology. 1991;113:336-343.

14 Gale WF, Totemeier TC. Smithells Metals Reference Book, 8th ed. Elsevier, London, UK; 2004.

Received: 18 Aug. 2020

Accepted: 11 Nov. 2020 